\title{
Políticas de avaliação em larga escala na educação básica: do controle de resultados à
}

intervenção nos processos de operacionalização do ensino

Flávia Obino Corrêa Werle*

\section{Resumo}

Este artigo discute o panorama da educação brasileira, destacando os processos de avaliação em larga escala implementados nas décadas de 1990 e 2000. Faz referência aos três níveis (federal, estadual, municipal) em que estas avaliações operam, e sua abrangência desde os segmentos iniciais da Educação Básica até a Pós-graduação. Analisa os últimos cinco anos como fase de síntese, estruturação e consolidação de um quadro geral de ação política referente a processos externos de avaliação em larga escala no Brasil, o qual passa de um nível de diagnóstico, para o de significados pautados pelo pragmatismo e operacionalização.

Palavras-chave: Avaliação externa. Sistema de ensino. Políticas públicas.

\section{Policies of large-scale assessment in basic} education: from the control of the results to intervention in cases of operationalization of teaching

\section{Abstract}

This article discusses the panorama of education in Brazil, highlighting the processes of large-scale assessments implemented in the 1990s and 2000s. It refers to the three levels in which these assessments are operating (federal, state and municipal or macro, meso and micro), and their coverage from the initial segments of Basic Education to Postgraduate studies. It analyzes the last five years as a stage of synthesis, structure and consolidation of a general

* Dra. em Educação; professora, Universidade do Vale do Rio dos Sinos (Unisinos).

E-mail: flaviaw@unisinos.br 
framework for political action related to external processes of large-scale assessment in Brazil, from a diagnostic level to the meanings guided by pragmatism and operationalization .

Keywords: External evaluation. Education system. Public policies.

\section{Políticas de evaluación en larga escala en la educación básica: del control de resultados a la interverción en los procesos de operacionalización de la enseñanza \\ Resumen}

Este artículo discute el panorama de la educación brasileña y destaca los procesos de evaluación en larga escala implementados en las décadas de 1990 y 2000. Se refiere a tres niveles (federal, provincial y municipal) en que estas evaluaciones actúan y su alcance desde los segmentos iniciales de la Educación Básica hasta el Posgrado. Analiza los últimos cinco años como fase de síntesis, estructuración y consolidación de un cuadro general de acción política referente a procesos externos de evaluación en larga escala en Brasil, el cual pasa de un nivel de diagnóstico para otro de significados pautados por el pragmatismo y la operacionalización. Palabras-clave: Evaluación externa. Sistema de enseñanza. Políticas públicas.

\section{Introdução}

Proponho uma discussão ${ }^{1}$ acerca do Estado e suas manifestações quais sejam, as políticas públicas. Explico melhor, inspirada em Muller e Surel (2004), entendo que, nos dias de hoje, o Estado é percebido através de sua ação. Estudar o Estado é analisar a sua ação pública, é compreender suas lógicas de intervenção, identificar suas dinâmicas articulações com a sociedade. Falar do Estado é referir-se a processos e dispositivos político-administrativos que são tanto normativos como voltados para a ação e coordenados ao redor de objetivos.

A noção de quadro geral das políticas públicas envolve duas dimensões ou duas lógicas, uma focada na ação e a outra, no sentido. Um programa de ação em políticas públicas compreende "uma combinação específica de leis, de atribuições de créditos, de administrações e de pessoal voltados para a realização de um conjunto de objetivos mais ou menos claramente definidos", enquanto que uma estrutura de sentido envolve a mobilização de "elementos de valor e de conhecimento, assim como instrumentos de ação particulares, com o fim de realizar objetivos construídos pelas trocas entre os atores públicos e privados" (MULLER; SUREL, 2004, p. 18-19).

1 Uma primeira versão deste artigo foi apresentada em evento da Universidade Integrada Regional (URI)

Frederico Westphalen, em 23 de julho de 2010. 
Minha intenção é traçar o quadro geral das políticas públicas brasileiras do campo da educação, rememorando as ações empreendidas, identificando a instituição de políticas e estratégias de ação, e o sentido que pode ser apreendido do conjunto. Indico o panorama das políticas educacionais nas últimas décadas para então apresentar o diferencial daquelas que operacionalizam e efetivam a realização de objetivos educacionais proclamados nos últimos anos. 0 foco principal são as ações do Estado relacionadas com a avaliação em larga escala da Educação Básica. Refiro-me ao Estado brasileiro nos últimos anos, especialmente considerando as ações estabelecidas, predominantemente, a partir de 2005, identificadoo com o sentido de modernização, racionalidade e eficácia - "eficácia, porque assente na monoracionalidade, impõe-se de forma independente dos contextos institucionais e organizacionais" (LIMA; AFONSO, 2002, p. 23).

\section{Retomando aspectos legais}

Com a finalidade de lembrar importantes elementos do quadro legal da educação brasileira e as modificações sócio-históricas que os têm impactado, apenas três aspectos aqui serão considerados, a faixa de obrigatoriedade, as questões participativas na educação e os procedimentos de avaliação em larga escala.

\section{Ampliação da faixa de obrigatoriedade}

Nos anos sessenta, com a Lei $n^{\circ}$. 4.024 (BRASIL, 1961), o ensino obrigatório abrangia as quatro primeiras séries do primário. 0 ingresso no ciclo ginasial exigia aprovação em exame de admissão, o qual constituía barreira para a continuidade de estudos. Na década de 1970, com a Lei nº 5.692 (BRASIL, 1971), a obrigatoriedade passou para a faixa etária de 7 a 14 anos, abrangendo o ensino de $1^{\circ}$. Grau, do qual já havia sido eliminado o exame de admissão, mas que enfrentava 0 desafio (apenas para citar um deles) de integrar e ofertar iniciação para o trabaIho articulada à educação geral a todos os alunos.

A década de 1980 caracteriza-se pelo processo de abertura política; no fim da ditadura militar, início dos anos oitenta, o Brasil convivia com alta inflação e um período de estagnação econômica. 0 tecnicismo e a profissionalização compulsória no ensino de segundo grau e a desarticulação entre os três graus de ensino haviam chegado ao seu limite. A proposta de integrar a educação geral e a formação para o trabalho desde 0 primeiro grau não atingira seus objetivos. A exigência de profissionalização em todos os cursos do ensino de segundo grau provocara desqualificação da formação de nível médio. A nação clamava por redemocratização e desencadeava tal processo. Era momento de intensas expectativas de participação e abertura dos processos de gestão da educação, mobilizando a sociedade e os educadores. Em 1988, uma nova Constituição Federal (BRASIL, 1988), a Constituição Cidadã - deu espaço para intenções e projetos abafados há muito, contemplando demandas de democratização. 
Se a década de oitenta foi de abertura política e de democratização, a década de 1990 foi de reformas do Estado, de parcerias entre Estado e sociedade civil, privatizações e emergência do Terceiro Setor. Ter presente este cenário é importante para acompanhar as ações do Estado na educação ao longo deste período.

A Constituição (BRASIL, 1988) e a Lei de Diretrizes e Bases da Educação Nacional (LDBEN), Lei $n^{\circ} .9 .394$ (BRASIL, 1996), reafirmam o Ensino Fundamental obrigatório e gratuito, assegurando sua oferta para jovens e adultos que a ele não tiveram acesso, bem como a progressiva universalização do Ensino Médio gratuito. Avançando e dando sentido concreto a esta expectativa de extensão progressiva da obrigatoriedade para o Ensino Médio, a Emenda Constitucional $n^{\circ} .59$ (BRASIL, 2009) amplia a faixa de obrigatoriedade e gratuidade estendendo-a dos 4 aos 17 anos. Verifica-se, portanto, que nos últimos cinquenta anos ocorreu uma considerável ampliação na faixa de responsabilização do Estado brasileiro quanto à oferta de ensino obrigatório e gratuito: anos sessenta de 7 a 10 anos e, em 2009, passa a abranger dos 4 aos 17 anos.

Quadro 1 - Ampliação da faixa de obrigatoriedade do ensino no Brasil -1961 - 2010.

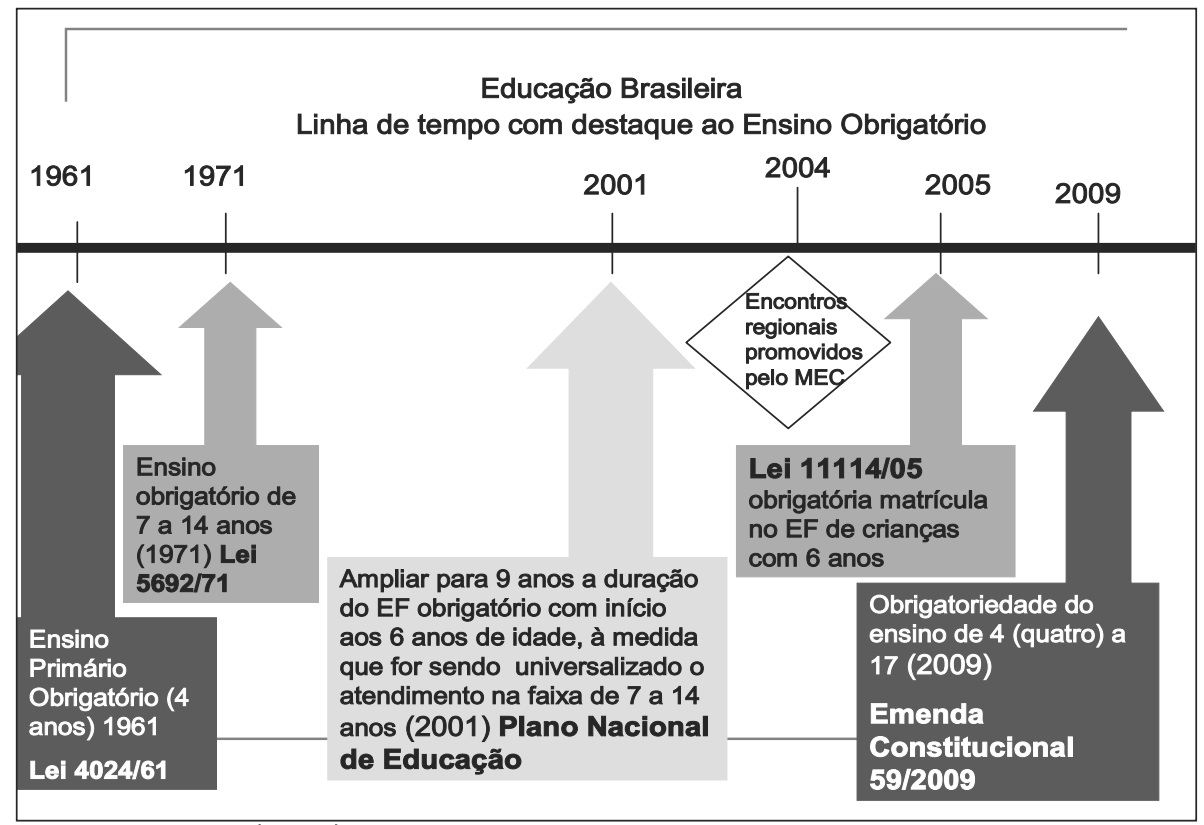

Fonte: A autora (2010). 


\section{Gestão democrática e garantia de padrão de qualidade como principios da educação}

No que se refere ao processo de democratização da educação cabe lembrar um dos capítulos da Constituição (BRASIL, 1988), o terceiro, que explicita ações no campo educacional, proclama princípios de igualdade de acesso e permanência na escola, gratuidade, liberdade, garantia de padrão de qualidade e gestão democrática.

A Constituição (BRASIL, 1988) inova fortemente na afirmação da gestão democrática e no tratamento dos componentes da federação para os quais ela define paridade, simetria, entre os três entes federados, Estados, Municípios e União. Ou seja, a possibilidade dos municípios constituírem seus sistemas de ensino de forma mais autônoma, embora referenciados ao quadro regulatório nacional, é uma força emergente importante a partir da Constituição Federal (BRASIL, 1988):

Art. 211 - A União, os Estados, o Distrito Federal e os Municípios organizarão em regime de colaboração seus sistemas de ensino. $\S 1^{\circ} \mathrm{A}$ União organizará o sistema federal de ensino e o dos Territórios, financiará as instituições de ensino públicas federais e exercerá, em matéria educacional, função redistributiva e supletiva, de forma a garantir equalização de oportunidades educacionais e padrão mínimo de qualidade do ensino mediante assistência técnica e financeira aos Estados, ao Distrito Federal e aos Municípios.

$\S 2^{\circ}$ Os Municípios atuarão prioritariamente no ensino fundamental e na educação infantil.

$\S 3^{\circ}$ Os Estados e o Distrito Federal atuarão prioritariamente no ensino fundamental e médio.

$\S 4^{\circ} \mathrm{Na}$ organização de seus sistemas de ensino, os Estados e os Municípios definirão formas de colaboração, de modo a assegurar a universalização do ensino obrigatório.

Obrigatoriedade mais extensiva e o incentivo à gestão democrática são elementos importantes, mas é preciso também ressaltar a grande responsabilidade da União, mencionada na Constituição Federal (BRASIL, 1988), no que se refere a assegurar um padrão mínimo de qualidade. Na Lei no. 9.394 (BRASIL, 1996), o tema da qualidade é reafirmado e enfatizado. A ampliação da obrigatoriedade tem implicações no padrão mínimo de qualidade, o qual é especificado na LDBEN (BRASIL, 1996), artigo $4^{\circ}$, inciso IX, quando refere o dever do Estado em garantir

IX - padrões mínimos de qualidade de ensino, definidos como a variedade e quantidade mínimas, por aluno, de insumos indispensáveis ao desenvolvimento do processo de ensino-aprendizagem. 
Gestão democrática, obrigatoriedade e qualidade do ensino são aspectos centrais da ação do Estado na Educação Básica brasileira o que exige, para sua efetivação, a colaboração entre os entes federados². A União é reafirmada como a instância coordenadora da política educacional, o que fica explicitado no artigo $8^{\circ}$ da LDBEN (BRASIL, 1996). Dentre suas incumbências está a de assegurar o processo nacional de avaliação do rendimento escolar no ensino Fundamental, Médio e Superior, em colaboração com os sistemas de ensino, objetivando a definição de prioridades e a melhoria da qualidade do ensino, bem como assegurar processo nacional de avaliação das instituições de Educação Superior, a avaliação de cursos das IES, para o que deverá ter acesso a todos os dados e informações necessários de todos os estabelecimentos e órgãos educacionais (BRASIL, 1996, artigo 9º, incisos VI, VIII, $\S 2^{\circ}$ ). Portanto, no que se refere à avaliação a União tem um papel determinante no contexto da organização federativa nacional.

\section{Avaliação em larga escala: retrospecto de iniciativas}

É no ano de 1988 que são ensaiadas as experiências de avaliação em larga escala na Educação Básica que, com reformulações importantes, ainda hoje estão em vigor. 0 Ministério da Educação (MEC) realiza uma aplicação piloto do Sistema Nacional de Avaliação do Ensino Público (Saep) de $1^{\circ}$ grau, nos estados do Paraná e Rio Grande do Norte. Ora, duas eram as forças impelindo a educação no sentido de fortalecer os procedimentos de avaliação. Por um lado, o Banco Mundial demandava a análise de impacto do Projeto Nordeste realizado no âmbito do acordo entre o MEC e o Banco Internacional para Reconstrução e Desenvolvimento (Bird) ${ }^{3}$ e, por outro, o MEC tinha interesse em realizar uma avaliação mais ampla do ensino público. Como afirma Bonamino (2002, p. 94), havia interesses e uma certa "paternidade dos agentes internos sobre este sistema de avaliação", com o que Peroni (2003) também concorda por identificar nas discussões sobre a educação nos anos oitenta os temas de democratização, transparência de gestão e qualidade.

Em 1990, inicia o $1^{\circ}$ ciclo Saep, desenvolvido de forma descentralizada pelos estados e municípios. Com a participação ativa de professores e técnicos das Secretarias de Educação, desenvolvem-se os ciclos de 1990 e 1993, tanto no tratamento como na análise dos dados, conforme princípio de descentralização operacional e organizativa. É a partir de 1992 que a avaliação externa em larga escala passa para responsabilidade do Instituto Nacional de Pesquisas e Estudos Educacionais Anísio Teixeira (Inep), órgão do MEC. Nesta época, paralelamente, iniciam as primeiras experiências de avaliações em nivel estadual (BONAMINO, 2002, p. 64).

2 Mais adiante neste texto, demonstra-se que, além do regime de colaboração entre a União, os Estados e os Municípios e Distrito Federal, as organizações não governamentais se constituem também como agentes no espaço das políticas educacionais brasileiras.

3 International Bank for Reconstruction and Development que constitui com outros organismosde ajuda e desenvolvimento internacional o Banco Mundial. 
No ano de 1993, desenvolve-se o $2^{\circ}$ ciclo Saep, mantendo a perspectiva participava da fase anterior. Nesta fase, o Inep convoca especialistas em gestão escolar, currículo e docência de Universidades para analisar o sistema de avaliação, buscando assim legitimidade acadêmica e reconhecimento social (BONAMINO, 2002, p. 100).

É no ano de 1995, entretanto, que o sistema de avaliação assume um novo perfil reforçado por empréstimos com o Banco Mundial (BM), e pela a terceirização de operações técnicas, passando a chamar-se Sistema de Avaliação da Educação Básica (Saeb). A partir daí, as funções do MEC se restringem à definição dos objetivos gerais do Sistema de Avaliação, os professores da Universidade passam a ter "posição subalterna", bem como as administrações locais veem reduzida sua ação ao simples apoio logístico na fase de aplicação das provas. A partir de 1995, portanto, ocorre uma reordenação na avaliação em larga escala da educação básica na direção de uma centralização de decisões na União e um correspondente afastamento da participação dos Estados o que reforça que estes criem suas próprias estruturas avaliativas.

A avaliação passa a ocorrer de dois em dois anos, focando dois componentes curriculares: Português (leitura) e Matemática (solução de problemas). A característica do Saeb é ser uma avaliação amostral de $4^{a}$ e $8^{a}$ séries do Ensino Fundamental e de $3^{\circ}$ ano do Ensino Médio, envolvendo estudantes das redes públicas e privada, de zonas urbanas e rurais, oferecendo informações passiveis de serem tratadas por localização rural ou urbana, por dependência administrativa, por unidade da federação, por região e na totalidade do país.

Cabe ressaltar que, no final do ano de 1996, a Lei №. 9.394 (BRASIL, 1996) é promulgada, reafirmando o papel da avaliação externa e tornando imperativo o processo de avaliação, exigindo sua universalização, conforme conteúdo do

\footnotetext{
Art. 87. É instituída a Década da Educação, a iniciar-se um ano a partir da publicação desta Lei. [...] § $3^{\circ}$ Cada Município e, supletivamente, o Estado e a União, deverá: [...] IV integrar todos os estabelecimentos de ensino fundamental do seu território ao sistema nacional de avaliação do rendimento escolar (BRASIL, 1996).
}

No ano de 1996, outro importante passo foi dado, agora no sentido do financiamento da Educação Básica, assegurando condições para a qualidade da educação e o provimento de insumos insdispensáveis em quantidade e variedade. Trata-se da Emenda Constitucional 14 (BRASIL, 1996a), que cria o Fundo de Manutenção e Desenvolvimento do Ensino Fundamental e de Valorização do Magistério (Fundef), implementado em 1998 com vigência até 2006, visando garantir um valor por aluno, correspondente a um padrão mínimo de qualidade de ensino, o qual, definido nacionalmente, assegura também recursos para o pagamento de professores em efetivo exercício no magistério no ensino fundamental. Dez anos depois, considerando a expectativa de ampliação da obrigatoriedade ao Ensino Médio 
e à Educação Infantil, a Emenda Constitucional no. 53 (BRASIL, 2006) cria o Fundo de Manutenção e Desenvolvimento da Educação Básica e de Valorização dos Profissionais da Educação (Fundeb), regulamentado pela Lei $n^{\circ} .11 .494$ (BRASIL, 2007) e pelo Decreto $n^{\circ}$. 6.253 (BRASIL, 2007), com vigência de 2007 até 2020.

Os mecanismos de financiamento do ensino são relevantes por assegurarem recursos para o cumprimento da orbigatoriedade, a melhoria da qualidade do ensino, a qualificação da Educação Básica, um valor por aluno e incremento da remuneração docente. Ou seja, estes mecanismos dão sentido aos princípios declarados na constituuição (BRASIL, 1988) e na LDBEN (BRASIL, 1996), pois são uma dimensão que possibilita a valorização do professor, das escolas e da educação.

0 sistema de avaliação vinha, portanto, se desenvolvendo ao longo da década de 1990, e, paralelamente, a ele contribuindo para sua consolidação e revisões os mecanismos de financiamento se consolidaram na legislação educacional.

A avaliação em larga escala, entretanto, na década de 1990 se desdobra em multiplas modalidades. A avaliação da Educação Básica, que se reduzia ao Saeb, amostral, focado em competências em leitura e matemática, passa a contar, em 1998, com outro instrumento, agora instituído com o objetivo de verificar o comportamento de saída do ensino médio, o Exame Nacional do Ensino Médio (Enem). Este extrapola o objetivo de avaliar as aprendizagens realizadas pelos concluintes do Ensino Médio no momento em que subsidia a engrenagem organizada nacionalmente para o ingresso no sistema federal de Educação Superior pública, substituindo, em muitos casos, a prática do vestibular como forma de seleção para o ingresso no Ensino Superior.

0 Enem foi recebido, inicialmente, com descrédito por parte das Universidades, e com reações contrárias, inclusive por parte dos estudantes. Uma das dificuldades era o pagamento de taxas para sua realização, frente ao que algumas secretarias de educação se dispuseram a arcar com os custos de inscrição dos estudantes das escolas públicas. Entretanto, o Enem foi progressivamente adquirindo espaço e força em decorrência de três eixos de questões. Primeiro, com a adesão de Universidades que passaram a considerar os resultados obtidos pelos estudantes para o ingresso no Ensino Superior, em segundo lugar, com o Programa Universidade para Todos (ProUni) cujo critério de ingresso no Ensino Superior apenas considera os resultados do Enem e, em terceiro lugar, com a implantação do Sistema de Seleção Unificada (Sisu) 4 .

4 O Sisu é gerenciado pelo MEC. Por meio deste sistema informatizado, são selecionados candidatos a vagas em cursos de graduação disponibilizadas pelas instituições públicas de Educação Superior participantes. As IES assinam um Termo de Participação que é o instrumento por meio do qual a instituição pública de educação superior formaliza sua opção pelo Sisu para a seleção e a ocupação das vagas nele inseridas. As IES que participam do Sisu utilizam a nota do Enem como única fase de seu processo seletivo. Os candidatos podem escolher até duas opções de curso de IES participantes do Sisu. Ao final do prazo de inscrição, o sistema seleciona automaticamente os candidatos melhor classificados em cada curso, de acordo com suas notas no Enem. São selecionados somente os candidatos classificados dentro do número de vagas ofertadas pelo Sisu em cada curso. 
O Sisu, criado e gerenciado pelo MEC é uma estratégia importante de fortalecimento e institucionalização do Enem. O Sisu consolida os resultados do Enem como prova única de seleção para instituições de Ensino Superior. Cada vez mais Instituições de Ensino Superior (IES) públicas, Universidades Federais, Universidades Estaduais e Institutos federais de educação, ciência e tecnologia, bem como IES particulares adotam o Enem como processo de seleção para ingresso em seus cursos de graduação. Os candidatos aos cursos das IES públicas participantes do SISU submetem-se a um processo centralizado de oferta de vagas, o que passa a configurar um sistema nacional de Ensino Superior público.

No ano de 1999, o Saeb inclui, além de Leitura e Matemática, a avaliação em dois outros componentes curriculares, História e Geografia, o que não foi sustentado ao longo dos anos. Ademais, além de instrumentos cognitivos, provas, a avaliação envolve instrumentos contextuais, questionários, cujo conteúdo inclui a escola e a infraestrutura, equipamentos e materiais, o perfil diretor e os mecanismos de gestão, os professores, seu perfil e suas práticas e, quanto aos alunos, suas características socioculturais e sua habilidade de estudo.

Concomitantemente, nos anos de 1997 e 1998, verifica-se a participação do Brasil em projetos internacionais de avaliação em larga escala sob a coordenação da Oficina da Unesco-Orelac ${ }^{5}$, prenunciando nova fase na sistemática de avaliação da Educação Básica. É no ano 2000 que o Brasil passa a participar do Programa Internacional de Avaliação de Estudantes (Pisa) ${ }^{6}$, organizado pela Organização para a Cooperação e o Desenvolvimento Econômico - $(O C D E$, o qual se realiza, a partir desta data, de três em três anos.

Nos anos noventa, portanto, os processos de avaliação em larga escala se difundem e passam a operar em sistemas educativos de vários países. Se, no final dos anos oitenta e início dos noventa os procedimentos de avaliação eram incipientes e o MEC neles envolvia agentes dos sistemas de ensino e docentes do ensino superior, após 1995 a avaliação é reforçada, terceirizada e consolidada como ação do poder público federal separando os diferentes níveis em que a avaliação da Educação Básica se processa. Apesar da centralização no Inep do sistema de avaliação, os Estados criam suas próprias modalidades de avaliação, assim como alguns municipios.

5 A Unesco é um organismo especializado do sistema das Nações Unidas. A Unesco fundou-se a 16 de novembro de 1945 com o objetivo de contribuir para a paz e a segurança no mundo mediante a educação, a ciência, a cultura e as comunicações. Seu principal objetivo é reduzir o analfabetismo no mundo. Incluem-se entre seus objetivos: a formação de professores, a criação de escolas, pesquisas para orientar a exploração dos recursos naturais, programas de preservação do patrimônio cultural e bens naturais além do desenvolvimento dos meios de comunicação. A Unesco atua em 112 países. Oficina Regional de Educación para América Latina y el Caribe (Orelac)

6 Programme International Student Assessment (Pisa) avalia jovens de 15 anos, no final da escolaridade obrigatória, qualquer que seja o tipo de escola em que estudem, focando temas que estes jovens necessitarão no futuro e avaliando como os jovens operam com os conhecimentos e aprendizagens. 0 conteúdo corresponde às áreas da leitura, matemática e ciências. 0 Pisa é uma prova que é aplicada a cada três anos, com um enfoque dominante em cada aplicação: em 2000 a ênfase esteve na leitura; em 2003, na matemática; em 2006, em ciências; em 2009, novamente na leitura. A ênfase em determinada área se dá pelo fato de que dois terços da parte do tempo da avaliação ( 2 horas) está destinada a essa área. "0 Pisa não objetiva [...] medir o alcance da formação geral moderna ou delinear o perfil de um currículo internacional” (AMARAL, 2008, p. 38). 
Na entrada do século XXI, o Brasil submete-se a avaliações internacionais e, é justamente no início deste século que a avaliação é fortemente incluída nos processos de planejamento educacional.

\title{
Avaliação em larga escala: referências do Plano Nacional de Educação
}

No ano de 2001, é promulgado, pela Lei no. 10.172 (BRASIL, 2001), o Plano Nacional de Educação (PNE), elaborado com a participação da sociedade, de associações e entidades de educadores e que, embora com criticas, foi concebido num processo de discussão democrática. 0 PNE desde a introdução anuncia a importância dos sistemas de avaliação em todos os níveis de ensino. A proposta é uma avaliação definida como prioridade associada ao desenvolvimento de sistemas de informação e de avaliação em todos os níveis e modalidades de ensino, de forma a aperfeiçoar os processos de coleta e difusão dos dados e de aprimoramento da gestão e melhoria do ensino.

Nas diretrizes para o Ensino Fundamental, o PNE reafirma a necessidade de consolidar e aperfeiçoar o Censo Escolar e o Saeb e de criar sistemas complementares nos estados e municípios, explicitando, dentre seus objetivos e suas metas, a necessidade de articular as atuais funções de supervisão e inspeção no sistema de avaliação, bem como a importância de:

\begin{abstract}
Assegurar a elevação progressiva do nível de desempenho dos alunos, mediante a implantação, em todos os sistemas de ensino, de um programa de monitoramento que utilize os indicadores do Sistema Nacional de Avaliação da Educação Básica e dos sistemas de avaliação dos estados e municípios que venham a ser desenvolvidos (BRASIL, 2001, não paginado, grifo nosso).
\end{abstract}

Com relação a diretrizes para o Ensino Médio, o PNE destaca que é essencial para o acompanhamento de resultados e correção de equívocos o estabelecimento de um sistema de avaliação à semelhança daquele do ensino fundamental, pois o Saeb, o Enem e os demais sistemas estatísticos são importantes mecanismos para promover a eficiência e a igualdade no Ensino Médio. Destaca-se que o Enem tinha sido criado recentemente, em 1998, quando da aprovação do PNE, em 2001, e neste 0 Enem saia reforçado, assim como o Saeb, mais antigo e consolidado como proposta de avaliação externa da educação.

Quanto ao Ensino Superior, o Plano (BRASIL, 2001) define metas relativas à sua expansão, além de recomendações de institucionalização de um amplo sistema de avaliação associado à ampliação dos programas de pós-graduação. Propõe também 
a criação de programas de fomento para que as próprias instituições de Ensino Superior constituam seus sistemas de avaliação institucional e de cursos, de forma a elevar os padrões de qualidade do ensino, da extensão e da pesquisa, programas estes, na medida do possível, nacionalmente articulados. 0 objetivo era associar a autonomia das Instituições, o reconhecimento e recredenciamento de cursos aos resultados das avaliações.

Há que ressaltar que o Ensino Superior, anteriormente ao PNE, desde 1996, vinha sendo avaliado pelo Exame Nacional de Cursos (ENC), usualmente chamado de Provão. Portanto, quando da aprovação do PNE, já existiam estratégias de avaliação de ampla envergadura relativas ao Ensino Fundamental, Médio e Superior - Saeb, Enem, ENC/Provão. 0 PNE reforça todos estes mecanismos de avaliação e, ao indicar objetivos e metas, direciona e encaminha para a sua operacionalização.

Quanto à formação de professores e valorização do magistério, o PNE apresenta um amplo cenário, destacando a importância da "avaliação do desempenho dos professores" na configuração da carreira do magistério. Dentre os objetivos e as metas para a formação de professores, inclui a promoção, em colaboração com os Municípios, Estados e União, de avaliação periódica da qualidade da atuação dos professores para oferecer subsídios que possam orientar programas de formação continuada de docentes.

Da mesma forma, no tópico de Financiamento e Gestão, estava anunciada a relevância da avaliação e do aprimoramento dos sistemas de informação, das bases de dados educacionais, dos processos de coleta e armazenamento de dados censitários e de estatísticas da educação nacional.

Desta maneira, poder-se-á consolidar um sistema de avaliação indispensável para verificar a eficácia das políticas públicas em matéria de educação. A adoção de ambos os sistemas [de informação e de avaliação] requer a formação de recursos humanos qualificados e a informatização dos serviços, inicialmente das secretarias, mas com o objetivo de conectá-las em rede com suas escolas e com o MEC (BRASIL, 2001, não paginado).

Dentre os objetivos e as metas de gestão e financiamento, o PNE especifica que é preciso estabelecer programas de formação de pessoal técnico para os setores de informação, de estatísticas educacionais, de planejamento e de avaliação.

38. Consolidar e aperfeiçoar o Sistema Nacional de Avaliação da Educação Básica - SAEB e o censo escolar. [...] 39. Estabelecer, nos Estados, em cinco anos, com a colaboração técnica e financeira da União, um programa de avaliação de desempenho que atinja, pelo menos, todas as esco- 
las de mais de 50 alunos do ensino fundamental e Médio. [...] 40. Estabelecer, nos Municípios, em cinco anos, programas de acompanhamento e avaliação dos estabelecimentos de educação infantil. 41. Definir padrões mínimos de qualidade da aprendizagem na Educação Básica numa Conferência Nacional de Educação, que envolva a comunidade educacional (BRASIL, 2001, não paginado).

A própria avaliação do PNE (BRASIL, 2001, não paginado) deve valer-se de

[...] dados e análises qualitativas e quantitativas fornecidos pelo sistema de avaliação já operado pelo Ministério da Educação, nos diferentes níveis, como os do Sistema de Avaliação da Educação Básica - SAEB; do Exame Nacional do Ensino Médio - ENEM; do Sistema de Avaliação do Ensino Superior (Comissão de Especialistas, Exame Nacional de Cursos, Comissão de Autorização e Reconhecimento), avaliação conduzida pela Fundação/Coordenação de Aperfeiçoamento de Pessoal de Nível Superior - CAPES.

Os destaques acima reafirmam o quanto o PNE, no inicio da década de 2000, acentua o reforçamento de sistemas de avaliação em larga escala já em andamento no país, incentiva todas as instâncias do Estado e estabelecimentos de Ensino Superior a desenvolver sistemas próprios de avaliação e aponta para a importância de integrar e aproveitar informações acumuladas nos bancos de dados do MEC decorrentes das avaliações já efetivadas do ensino fundamental à pós-graduação. Por outro lado, o PNE anuncia, também, que outras estratégias de avaliação seriam propostas com objetivos mais focados em escolas e cursos; que funções de supervisão e inspeção seriam articuladas a mecanismos de avaliação e que estratégias de monitoramento seriam criadas para "assegurar a elevação do nível de desempenho dos estudantes" e para "verificar a eficácia das políticas educacionais".

Ademais, na avaliação do Plano, está indicada a recomendação de envolvimento da sociedade civil e dos grupos diretamente interessadas e responsáveis pelos direitos da criança e do adolescente, de forma a realizarem o acompanhamento e a avaliação do Plano Nacional de Educação. Ora, esta referência expressa elementos decorrentes das reformas do Estado ocorridas na década de 1990 em direção à sua articulação com o terceiro setor, com a sociedade civil e o fomento de parcerias.

O PNE, portanto, em suas diretrizes, suas metas e seus objetivos indicava processos extensivos de avaliação em todos os níveis e delineava formas de operacionalizálos, indicando ações que, no decênio, foram sendo desenvolvidas e implementadas.

Argumentamos até agora que, nos anos oitenta, grandes foram as demandas por democratização da sociedade brasileira e da educação, que o acesso à escola e a concepção 
de faixa etária de obrigatoriedade foi sendo revista e que mecanismos de avaliação externa foram se estruturando, consolidando e diversificando de forma a envolver todos os niveis de ensino. 0 Estado em ação, portanto, apresentou um movimento de democratização, inclusão e atendimento mais amplo acompanhado de preocupações com a gestão, avaliação e acompanhamento da qualidade do ensino. Modificava-se, entretanto, a composição dos agentes que promoviam as políticas publicas e ações do Estado.

\section{Articulações da sociedade com as questões da educação}

A articulação com a sociedade civil sugerida como mecanismo para acompanhamento e avaliação do PNE vinha já ocorrendo, de forma ampla e diversificada, nos anos noventa, sendo incrementada, especialmente nos anos 2000, tanto pela proliferação de fundações, de organizações não governamentais (ONGs) e outros tipos de organizações da sociedade civil envolvidas com a educação, como pela ampliação do espaço da mídia como interlocutora e difusora da ação do Estado. Não é demais lembrar que, em 1998, foi criado o Programa dos Voluntários das Nações Unidas no Brasil, administrado pelo Programa das Nações Unidas para o Desenvolvimento (Pnud), dentro do sistema da Organização das Nações Unidas (ONU). É também o Pnud que, para aferir o grau de desenvolvimento do país, utiliza o Índice de Desenvolvimento Humano (IDH), e que lança, em 1998, o Atlas de Desenvolvimento Humano no Brasil, com o IDH de todos os municípios brasileiros. Esta referência explicita uma parte da trama de relações de agências nacionais e internacionais e a progressiva incorporação de indicadores e propostas relacionadas ao voluntariado e ao solidarismo em políticas de ação do Estado, seja no âmbito dos sistemas de ensino, seja no das escolas.São exemplos de envolvimento da iniciativa privada e da sociedade civil em ações de escolas públicas brasileiras as ações do Instituto Ayrton Senna ${ }^{7}$, incluindo Programas como Acelera Brasil - lançado em 1997 -, Se Liga, Circuito Campeão, Gestão Nota 10, SuperAção Jovem, Educação pela Arte, Educação pelo Esporte, Escola Conectada, dentre outros. 0 projeto Amigos da Escola ${ }^{8}$ da Rede Globo em parceria com o Instituto Brasil

7 O Instituto Ayrton Senna é uma Organização não-governamental (ONG ), sem fins lucrativos, fundada em 1994 com o objetivo de promover o desenvolvimento humano de crianças e jovens, em cooperação com empresas, governos, prefeituras, escolas, universidade e ONGs. São aliados do Instituto Ayrton Senna: Brasil Telecom, Intel, Microsoft, Nivea, Oracle, Siemens, Suzano Celulose e Papel, Vale, Instituto Votorantin, Instituto Unibanco, Instituto Vivo, Instituto Coca-Cola do Brasil, Copersucar, Credicard, Grendene, dentre outros. 0 Instituto cria, implementa, avalia e sistematiza tecnologias sociais voltadas para a educação formal, educação complementar e educação e tecnologias. Os programas do Instituto Ayrton Senna apresentam-se como soluções educacionais em grande escala para ajudar a "combater" os principais problemas da educação pública do País e muitos deles são instituídos como políticas públicas em redes de ensino do país. A Organização das Nações Unidas para a Educação, Ciência e Cultura (Unesco) concedeu, em 2003, o título de Cátedra em Educação e Desenvolvimento Humano ao Instituto Ayrton Senna devido ao trabalho de criação, implementação, avaliação e disseminação em larga escala de tecnologias sociais em desenvolvimento humano.

8 Amigos da Escola é um projeto criado pela Rede Globo de televisão e parceiros, com o objetivo de contribuir para o fortalecimento da educação e da escola pública de educação básica, procurando envolver especialmente pais e pessoas da comunidade em ações dentro das escolas públicas. 
Voluntário - Faça Parte ${ }^{9}$, Conselho Nacional de Secretários de Educação (Consed), e União Nacional dos Dirigentes Municipais de Educação (Undime), é outro exemplo. Ações da sociedade civil vêm, progressivamente, se multiplicando na forma de parcerias público-privadas, voluntariado, fundações voltadas para o desenvolvimento e para a educação, dentre outras formas.

Dentre as iniciativas da sociedade civil intervenientes na educação escolar, destaca-se o movimento Todos Pela Educação que articula representantes da sociedade civil, da iniciativa privada, organizações sociais, educadores e gestores da educação pública com a proposta de garantir Educação Básica de qualidade para todos os brasileiros até 2022, bicentenário da independência do País. Este movimento foi iniciado em 2005, por figuras de destaque do mundo empresarial, tendo sido nacional e oficialmente lançado em setembro de 2006. 0 Todos Pela Educação (2010) se auto-refere como um "projeto de nação" e não como projeto de uma organização específica. 0 movimento definiu cinco metas para a educação a serem alcançadas até 2022, quais sejam: 1) Toda criança e jovem de 4 a 17 anos estará na escola ${ }^{10}$; 2) Até $2010,80 \%$ e, até $2022,100 \%$ das crianças de 8 anos de idade estarão plenamente alfabetizadas; 3 ) Todo aluno aprenderá o que é apropriado para a sua série ${ }^{11}$; 4) Todo aluno concluirá o Ensino Fundamental até os 16 anos de idade e o Ensino Médio até os 19 anos; 5) 0 investimento em educação deve ser garantido e gerido de forma eficiente e ética.

A articulação das ações do Estado com a sociedade civil propiciou à mídia ocupar, progressivamente, espaço e legitimidade na divulgação de políticas, informações, projetos e ações relativas à educação. Um momento típico do espaço ocupado pela mídia na divulgação de políticas educacionais foi o lançamento do Plano de Desenvolvimento da Educação (PDE), em abril de 2007. Ao lado de notícias em jornais e revistas de grande circulação, o site do MEC informava as 28 estratégias do PDE com ícones apresentando imagens simples, estilizadas e infantilizadas, as quais conduziam a textos breves, em linguagem simples, assinados por jornalistas. $\mathrm{Ou}$ seja, a prática de autoridades da hierarquia e nomes respeitados da educação naci-

9 O Instituto Brasil Voluntário tem sede em São Paulo; é mantido pelo Banco Itaú, Banco Real, Dpaschoal, Coteminas, Goodyear, MEC, Consed, Amigos da Escola, Unesco, Undime, TAM. O Instituto Faça Parte fundado em 2001, tem como patrocinadores o Banco Itaú, Coteminas, Dpaschoal, Goodyear, TAM e como parceiros Amigos da Escola, ONU, MEC, Pnud, Undime, Consed, Fundação Itaú Social. O Instituto Brasil Solidário (IBS) - é uma organização sem fins lucrativos, ou seja, uma Organização da Sociedade Civil de Interesse Público (Oscip) - que tem como objetivo o desenvolvimento de programas sociais em comunidades desfavorecidas e com baixo Índice de Desenvolvimento Humano (IDH). Objetiva o desenvolvimento territorial sustentável, através da educação com foco na alfabetização, saúde, preservação do meio-ambiente, incentivo à cultura, arte, crédito e empreendedorismo.

10 Destaca-se que apenas em 2009, com a Emenda Constitucional 59 (BRASIL, 2009), esta ampliação da faixa etária foi incorporada na legislação.

110 impacto do movimento Todos Pela Educação na ação dos sistemas escolares e políticas educacionais pode ser avaliado, por exemplo, na seguinte especificação: "0 movimento Todos Pela Educação definiu, a partir da análise de especialistas em avaliação educacional, a pontuação mínima considerada adequada às séries: $4^{\mathrm{a}}$ série EF - Língua Portuguesa: acima de 200 pontos. Matemática: acima de 225 pontos; $8^{\text {a }}$ série EF - Língua Portuguesa: acima de 275 pontos. Matemática: acima de 300 pontos; $3^{\text {a }}$ série EM - Língua Portuguesa: acima de 300 pontos. Matemática: acima de 350 pontos” (TODOS PELA EDUCA$\tilde{A}(0,2010)$

Ensaio: aval. pol. públ. Educ., Rio de Janeiro, v. 19, n. 73, p. 769-792, out./dez. 2011 
onal apresentar as ações de políticas, legitimando-as, dá lugar à linguagem corriqueira, expressa em estratégia segmentada para todos os públicos. A divulgação do Exame Nacional de Ingresso no Magistério, em 24 de maio de 2010, seguiu estratégia semelhante. 0 mundo educacional e acadêmico foi surpreendido com a informação de que havia sido instituída uma prova para avaliar profissionais que tivessem concluido ou estivessem em vias de conclusão de cursos de formação inicial para a docência e que desejassem ingressar na carreira do magistério, tomando conhecimento pela divulgação que foi dada pelos meios de comunicação. As práticas de discussão com associações de profissionais da educação do conteúdo das políticas e de divulgação para o corpo profissional dos sistemas de ensino, mediante estratégias planejadas com foco neste público específico, que tem responsabilidade importante em tornar ato as políticas educacionais formuladas pela hierarquia dos sistemas, são abandonadas na primeira década do século XXI.

Esta explicação referente ao papel dos movimentos da sociedade civil é relevante, pois atualmente as ações de políticas públicas e, portanto do Estado, estão progressivamente a eles articuladas. 0 Estado abre a estas organizações espaço para intervenção nos processos escolares enquanto que, como poder público, assume, delimita e aprofunda ações de regulação.

\section{Avaliação em larga escala: ações da década de 2000}

Na primeira década do século XXI, os sistemas de avaliação em larga escala no Brasil continuaram em sua dinâmica, alguns sofrendo reformulações, outros tendo continuidade e alguns ainda criados como inovações. 0 quadro que segue estrutura, numa linha de tempo a partir da década de 1960, os principais documentos legais vinculados à educação, a situação geral do país e os períodos de ditadura e democratização, bem como os governos de Fernando Henrique Cardoso e Luiz Inácio Lula da Silva. Simboliza com retângulos levemente arredondados os principais eventos relativos aos sistemas de avaliação e políticas publicas educacionais mais recentes.

Quadro 2 - Educação brasileira: linha do tempo com destaque à avaliação em larga escala.

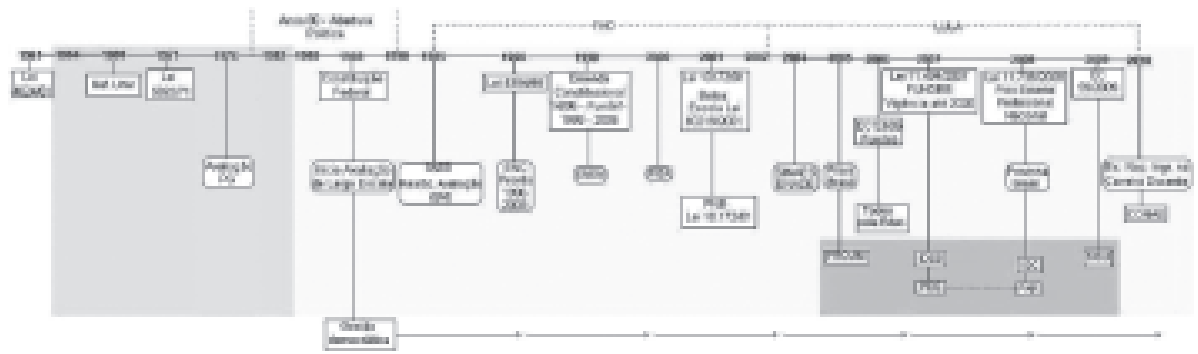

Fonte: A autora (2010). 
Desde os anos setenta, a pós-graduação brasileira estruturou um sistema de avaliação que hoje é reconhecido internacionalmente e que abrange a todas as áreas de conhecimento. 0 processo de avaliação do Ensino Superior voltado para cursos de graduação, se estruturou, mais fortemente, no final da década de 1990, recebendo da mídia grande espaço de divulgação.

O Provão era uma avaliação extensiva a todo o formando de curso de graduação presencial, com o objetivo de verificar os resultados do processo de ensino-aprendizagem, mediante provas de conteúdos específicos para cada curso superior. 0 ENC- Provão - que estava em curso desde 1996, vigente até 2003, foi reestruturado, dando lugar ao Sistema Nacional de Avaliação da Educação Superior (Sinaes). Este foi criado pela Lei $n^{\circ}$. 10.861 (BRASIL, 2004), seguindo uma proposta mais abrangente, lançando um olhar integrador para todas as dimensões envolvidas no Ensino Superior, ou seja, avaliando as instituições, os cursos e o desempenho dos estudantes, bem como o ensino, a pesquisa, a extensão, a responsabilidade social, a gestão da instituição, o corpo docente e as instalações. Quanto à avaliação do desempenho dos estudantes o Sinaes inclui o Exame Nacional de Desempenho de Estudantes (Enade), o qual tem como objetivo avaliar o rendimento dos alunos dos cursos de graduação em relação aos conteúdos programáticos, suas habilidades e suas competências.

\section{Medidas de operacionalização: dando sentido pragmático aos dados das avaliações}

0 quadro abaixo é uma tentativa de apresentar, sinteticamente, numa dimensão sincrônica e diacrônica as principais políticas publicas voltadas para a avaliação externa dos sistemas educativos. Ele representa, esquematicamente, as ações relativas a avaliações externas programadas pelas políticas publicas, agrupando as especificamente focadas na educação básica e as voltadas para o ensino superior. A seta que finaliza o esquema simboliza o que designamos de "Medidas de operacionalização", ou seja, políticas voltadas para a intervenção no funcionamento e gestão dos sistemas de ensino e escolas, as quase serão a seguir comentadas neste artigo. Embora os Quadros 2 e 3 não contenham as mesmas informações, eles são tentativas de representar sintética e graficamente as ideias argumentadas neste artigo. Assim as políticas que ocupam o quadrante direito inferior do Quadro 2, localizadas por sobre um retângulo sombreado, estão representadas no Quadro 3 pela seta inferior "Medidas de operacionalização". Estas "medidas de operacionalização", em nosso entender, são as que "dão sentido" (MULLER; SUREL, 2004) agrupam um conjunto de políticas que não são especificamente de avaliação, mas que se utilizam dos dados produzidos por estas, ou seja, mobilizam ações especificas criadas pelo Estado e outros atores para realizar os valores mais amplos inspiradores de todo o sistema. 
Quadro 3 - Representação das políticas públicas voltadas para a educação básica e para a educação superior em perspectiva sincrônica e diacrônica.

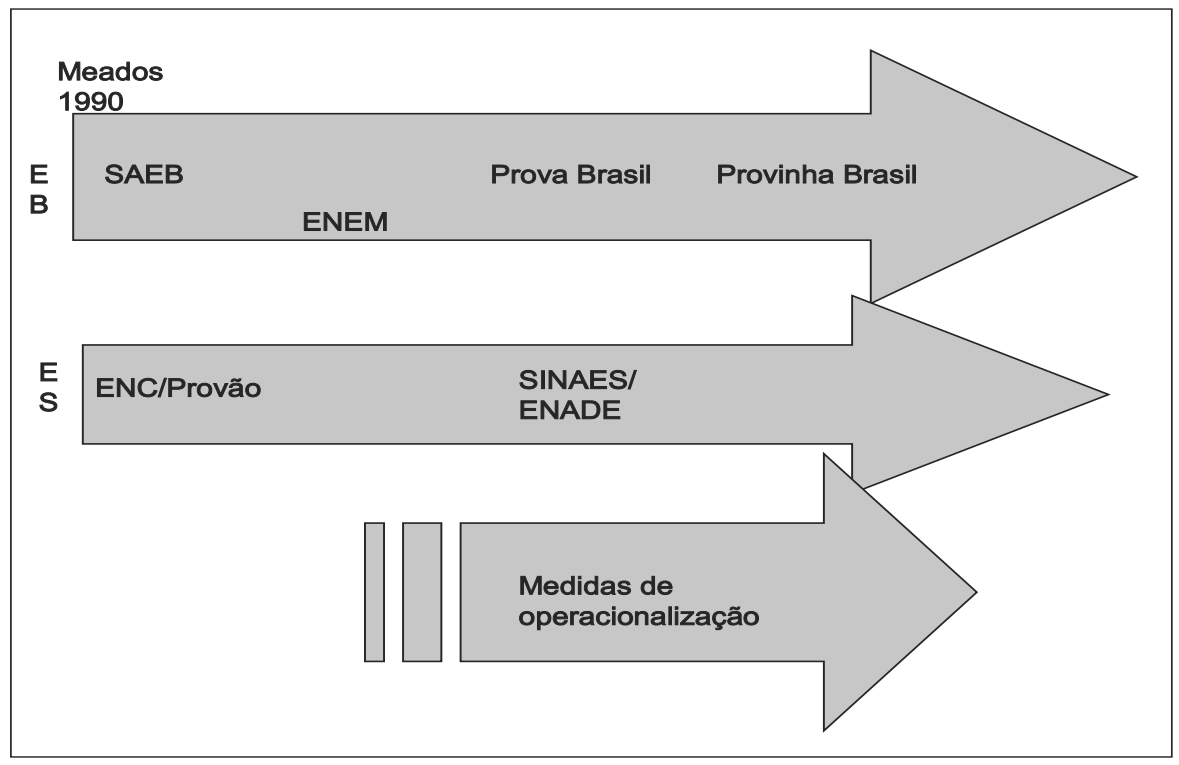

Fonte: A autora (2010).

0 ano de 2005 foi pródigo de inovações na sistemática de avaliação oriundas de propostas do Governo Federal. Foram criados a Prova Brasil e institucionalizado o Programa Universidade para Todos (Prouni). A Prova Brasil dá condições de instauração de criativas e inovadoras Medidas de Operacionalização e o Prouni já materializa uma política de operacionalização de ideias anunciadas com o Enem.

0 Prouni ${ }^{12}$ é uma modalidade de ingresso em cursos de graduação de instituições de Ensino Superior privadas, que utiliza, exclusivamente, a nota obtida no Enem. 0 Prouni é, pois, um instrumento que dá um sentido pragmático, funcional aos resultados do Enem, atribuindo importância à participação neste exame, fortalecendo-o como instrumento de política e de interação entre Estado e sociedade. Igualmente, no ano de 2009, o Sisu fortalece ainda mais o Enem, pois pelas notas do Enem os alunos são selecionados para ingresso em IES públicas.

O Sistema de Seleção Unificada (Sisu) criado e gerenciado pelo Ministério da Educação - é uma estratégia importante de fortalecimento e institucionalização do Enem pois consolida os resultados de tal exame adotado como prova única de seleção para instituições de

120 Prouni, criado pelo Governo Federal em 2004, e institucionalizado em janeiro de 2005, pela Lei $\mathrm{n}^{\circ}$ 11.096 (BRASIL, 2005), provê apoio para o Ensino Superior para pessoas de baixa renda frequentarem, com bolsas de estudo, integrais ou parciais, cursos de graduação de instituições de ensino superior privadas. 
Ensino Superior. Progressivamente, um maior numero de Instituições de Ensino Superior públicas, Universidades Federais, Universidades Estaduais e Institutos federais de educação, ciência e tecnologia, bem como IES particulares adotam o Enem como processo de seleção para ingresso em seus cursos de graduação. Os candidatos aos cursos das IES públicas participantes do SiSU submetem-se a um processo centralizado de oferta de vagas o que passa a configurar um sistema nacional de Ensino Superior público.

Se o processo de ingresso no Ensino Superior foi alterado com a utilização dos resultados do Enem e a criação do Prouni e Sisu, e se a avaliação de cursos e instituições de Ensino Superior foi reforçada pelo Sinaes e Enade, na Educação Básica, outros processos avaliativos foram introduzidos, como a Prova Brasil.

A Prova Brasil, criada em 2005 e aplicada de dois em dois anos, avalia, tal como o Saeb, habilidades de leitura e de resolução de problemas, mas diferencia-se daquela, em sua abrangência universal a todos os alunos de $4^{\text {a }}$ e $8^{\text {a }}$ séries do Ensino Fundamental de escolas públicas situadas em zonas urbanas, contanto que pertençam a turmas de 20 alunos ou mais. A informação oficial é que, por ser universal abrange todos os estudantes das séries indicadas, "expande o alcance dos resultados oferecidos pelo Saeb" (INEP, 2009), com a vantagem de apresentar informações que discriminam os resultados para cada município e cada escola participante.

Igualmente, no ano de 2005, surgem as primeiras iniciativas do movimento Todos Pela Educação, mencionado anteriormente, o qual é institucionalizado em 2006. No ano seguinte, o governo federal o resignifica e rearticula no PDE, dando origem ao Compromisso Todos Pela Educação ${ }^{13}$. Assim, uma ação marcante no direcionamento das políticas de avaliação fazendo com que elas operem - produzam efeitos e não apenas números -, nos sistemas escolares é a criação do PDE - e com ele do Índice de Desenvolvimento da Educação Básica (Ideb). É portanto, no ano de 2007, que são rearticuladas muitas ações de políticas de forma a atribuir um sentido mais operacional às avaliações que vinham sendo realizadas nos diferentes niveis escolares.

0 PDE, lançado em 24 de abril de 2007, abrange metas a Educação Infantil, Ensino Fundamental, Educação Profissional, Educação de Jovens e Adultos, Formação de Professores, dentre outras áreas. Sua concepção é marcada pelo predomínio do executivo, centralização e viés neoliberal no que toca a preocupação com a modernização e a eficácia do Estado, valorização do aparato técnico, controle e centralização. Nele é forte o eixo de emulação e controle dos sistemas de ensino (WERLE, 2009).

130 Compromisso Todos pela Educação é representado pelo governo federal como um plano de metas que compõe o Plano de Desenvolvimento da Educação e que tem por base o regime de colaboração a partir da conjugação dos esforços da União, Estados, Distrito Federal e Municípios. 0 Compromisso funciona como um contrato de gestão entre a União e os Estados, os Municípios e o Distrito Federal, possibilitando o repasse de recursos e a assistência técnica vinculados a metas e ao atendimento a diretrizes de trabalho, tendo em vista a melhoria do Índice de Desenvolvimento da Educação Básica (Ideb). 
0 Ideb, elemento central do PDE, é calculado a partir dos resultados da Prova Brasil e do fluxo escolar indicado pelo censo educacional. 0 ldeb, não apenas situa o nível alcançado pela escola e pela respectiva rede de ensino, mas, no contexto do PDE e do Compromisso Todos Pela Educação, possibilita o exercício de prospecção de metas a serem alcançadas em direção à melhoria da qualidade de ensino, tendo em vista um nível considerado mínimo a ser atingido em 2021, o que converge com a perspectiva temporal do movimento Todos Pela Educação. Ora, a criação do Ideb só foi possivel mediante as informações oferecidas pela Prova Brasil. Mas a articulação de dados oriundos do Censo e da Prova Brasil permitiram a construção de um indicador que se torna meta a ser obtida pelos sistemas de ensino.

Um programa estratégico do PDE é o Plano de Metas Compromisso Todos pela Educação ${ }^{14}$, instituído pelo Decreto $n^{0} .6 .094$ (BRASIL, 2007), que enfatiza o regime de colaboração entre os entes federados, envolvendo primordialmente a decisão política, a ação técnica e o atendimento da demanda educacional, tendo em vista os objetivos de melhoria dos indicadores educacionais.

Em 2007, é criado e implementado, em 2008, o Programa Mais Educação pela Portaria Interministerial no 17/2007 (EDUCAÇÃO, 2007), cujo objetivo é a ampliação da oferta de atividades educativas nas escolas públicas. É constituido por atividades optativas, oferecidas ao estudante no contra-turno, abrangendo vários campos de ação, tais como acompanhamento pedagógico, meio ambiente, esporte e lazer, direitos humanos, cultura e artes, cultura digital, prevenção e promoção da saúde, educomunicação, educação científica e educação econômica. Estas atividades complementares atuam no sentido de fortalecer a influencia da escola em termos de melhoria da cultura da comunidade e a qualificação do ensino.

0 programa visa a fomentar atividades para melhorar o ambiente escolar, tendo como base estudos desenvolvidos pelo Fundo das Nações Unidas para a Infância (UNICEF), utilizando os resultados da Prova Brasil de 2005. Nesses estudos destacou-se o uso do "Índice de Efeito Escola - IEE", indicador do impacto que a escola pode ter na vida e no aprendizado do estudante, cruzando-se informações socioeconômicas do município no qual a escola está localizada (EDUCAÇÃO, 2007, não paginado).

No atendimento da proposta incluída no Compromisso Todos Pela Educação referente a "alfabetizar as crianças até, no máximo, os oito anos de idade, aferindo os resultados por exame periódico específico", no ano de 2008, é instituída a Provinha Brasil, que se constitui em mais um instrumento de avaliação, agora focando os resultados das séries iniciais do Ensino Fundamental.

140 Plano de Metas Compromisso Todos pela Educação é composto de três partes. A primeira enfoca a gestão educacional e inclui 18 programas, a segunda a formação de professores e de profissionais da educação, envolvendo 21 programas e a terceira refere-se a infraestrutura e apoio educacional, com 25 programas. 
É também, em 2008, instituído o Índice Geral de Cursos (IGC), o qual, como o Saeb, Prova Brasil, Enem, Provinha Brasil, Enade e Sinaes, é articulado pelo Inep. 0 IGC é um indicador de qualidade de instituições de Educação Superior que agrega informações obtidas mediante outros instrumentos de avaliação, considerando, em sua composição, a qualidade dos cursos de graduação e de pós-graduação (mestrado e doutorado). Ou seja, o IGC agrega dados das avaliações Enade e dos cursos de pós-graduação das Instituições de Ensino Superior, conforme os critérios da Coordenação de Aperfeiçoamento de Pessoal de Ensino Superior (Capes).

No mesmo ano de 2008, outro desdobramento importante articulado ao PDE e aos resultados obtidos na Prova Brasil e no Censo Escolar, sintetizados no Ideb, começa a operar na educação brasileira. Trata-se do Plano de Ações Articuladas (PAR) que vincula todas as transferências voluntárias e assistência técnica do MEC aos municípios, estados e Distrito Federal à adesão ao Plano de Metas Compromisso Todos pela Educação e ao Plano de Ações Articuladas. O PAR dentro de uma proposta de gestão estratégica e transparência de ações (está disponível para consulta pública na internet) envolve na forma de uma autoavaliação dos sistemas o preenchimento de fichas diretamente num sistema informatizado gerenciado pelo MEC. 0 PAR está organizado em diferentes eixos (Gestão educacional, Formação de professores e dos profissionais de serviço e apoio escolar; Práticas pedagógicas e avaliação e Infra-estrutura física e recursos pedagógicos), cada um dos quais desdobrados em áreas de atuação, indicadores e critérios. 0 preenchimento deste instrumento resulta em diversos elementos: um diagnóstico, o detalhamento de ações necessárias para superar as deficiências, a indicação das necessidades de apoio técnico do MEC (termo de cooperação) do que resultam ações que geraram convênio, ou seja, a liberação de recursos financeiros.

Em 2009, o MEC lança o Programa Segundo Tempo (PST), para incrementar a prática de esportes e com isto ampliar o tempo de permanência dos alunos na escola, no que se articula com o Programa Mais Educação, criado em 2007. Ambos, portanto, têm como objetivo qualificar a Educação Básica na linha de uma educação em tempo integral, embora estas iniciativas não sejam extensivas a todas as escolas do país.

No ano de 2010, é instituida nova estratégia de avaliação, agora focando o corpo docente. Trata-se do Exame Nacional de Ingresso na Carreira Docente, instituido pela Portaria Normativa no. 14, de 21 de maio de 2010, cujos objetivos são a "avaliação de conhecimentos, competências e habilidades para subsidiar a contratação de docentes para a educação básica no âmbito dos Estados, do Distrito Federal e dos Municipios"; "oferecer um diagnóstico dos conhecimentos, competências e habilidades dos futuros professores para subsidiar as políticas públicas de formação continuada" e "construir um indicador qualitativo que possa ser incorporado à avaliação de políticas públicas de formação inicial de docentes" (Artigos $1^{\circ}$ e $2^{\circ}$ da Portaria Normativa 14/ 
2010). Este novo mecanismo de avaliação parece responder, no âmbito brasileiro, à proposta da Organização para a Cooperação e Desenvolvimento Econômico (OCDE), para um programa de avaliação de professores que verifica a atmosfera de aprendizagem, as relações professor-aluno, a qualidade e o estilo de ensino, para o qual, como afirma Amaral (2008, p. 45ss) em capitulo intitulado "Depois do PISA, PITA", sendo Pita a sigla para Programa Internacional de Avaliação de Professores - Programme International Teachers Assessment, "mais de vinte países já confirmaram sua participação na comparação de conhecimento, competência e cultura dos professores".

\section{Encaminhando conclusões}

0 quadro geral de políticas públicas de educação apresenta uma estrutura de avaliação implementada no final dos anos oitenta e incrementada a partir de 1995 pelo Saeb. Além do Saeb, vários outros instrumentos de avaliação vão sendo criados com objetivos específicos e mais delimitados. 0 ENC-Provão, focalizando cursos de graduação de Nivel Superior, em 1996, e, com foco no desempenho de concluintes do Ensino Médio, o Enem, em 1998. A avaliação em larga escala é, no sistema educacional brasileiro, uma proposta com origem no governo federal, nos estados, em alguns municípios e também com origem internacional. Com o ano 2000, o Brasil participa do Pisa. Internamente, continua mantendo a diversificação de suas propostas de avaliação de larga escala. Em 2004, o ENC se reestrutura na forma de Enade e Sinaes, e, em 2005, ocorre a primeira aplicação da Prova Brasil, que constitui um marco importante por possibilitar a especificação de informações por município e escola.

É nesta fase que as metas formuladas no PNE $^{15}$ e os dados das avaliações em larga escala são rearticulados e alçados para um nivel mais operativo, favorecendo ações mais pragmáticas e interventivas nos sistemas de ensino. Trata-se do Prouni e Sisu, que utilizam os dados do Enem, modificando a prática de vestibulares e fortalecendo de maneira mais definitiva o Enem. Trata-se também do PDE, IDEB, PAR, Mais Educação e PST, que dão um sentido mais operativo aos dados das avaliações e propõem estratégias concretas de interferência no quadro da educação básica. Trata-se também do IGC, que dá novo sentido aos resultados da avaliação da Capes, do Enade e Sinaes.

Este estudo demonstra as

[...] intertextualidades promovidas por uma espécde novo senso comum educacional, produzido por agências e organismos internacionais, difundido através de recomendações relatórios ou livros brancos, e especialmente recontextualizados pela comunicação social de massas e por instituições de âmbito nacional (LIMA; AFONSO, 2002, p. 8).

15 Durante os 10 anos de vigência do Plano Nacional de Educação não houve um processo continuo e amplo de avaliação de suas metas. Entretanto, seu conteúdo continuava sendo perseguido e muitas das ações propostas no final da primeira década do século XXI desdobram e operacionalizam objetivos nele formulados. 
Nosso argumento neste estudo é, portanto, que o projeto de avaliação em larga escala em desenvolvimento desde o final da década de 1980, desdobrado ao longo de vinte anos, é reforçado a partir de 2005. Reforçado por receber importante legitimação a partir de ações pragmáticas vinculadas ao rankeamento de instituições, escolas, redes municipais e estaduais, à liberação de recursos, à valorização da "transparência" para a sociedade e à necessidade de qualificação da educação. Reforçado pela criação de novos índices e sistemas de seleção que valorizam os resultados de outras avaliações, que instituem novos parâmetros de comparações entre as instituições do sistema educacional. Pode-se levantar a hipótese de que as políticas de avaliação não estejam presentes no cenário educacional brasileiro simplesmente para produzir comparações e emulação, mas para responder a estratégias gerencialistas de modernização e racionalização voltadas para resultados.

0 panorama das políticas educacionais evidencia também a emergência de tecnologias digitais na administração da educação e a centralização do controle que elas proporcionam. A padronização de áreas, indicadores e critérios presente nos instrumentos de coleta de dados retira a escola de um patamar de autoidentidade formulada a partir de seu próprio olhar para lançá-la como organização caracterizada por uma linguagem padrão universalizante e unificadora. Lima $(2002$, p. 17) fala-nos das perspectivas neotaylorianas presentes nas estratégias de políticas educacionais atuais. O PAR evidencia 0 "taylorismo informático" referido por Lima. A crença na capacidade reguladora dos números e índices produzidos pelas avaliações é reforçada por estratégias de planejamento como o PAR e outras modalidades de ação discutidas neste artigo.

\section{Referências}

AMARAL, M. N. de C. P. Ninguém ensina ninguém: aprende-se. São Paulo: Edusp, Fapesp, 2008.

BONAMINO, A. Tempos de avaliação educacional. Rio de Janeiro: Quartet, 2002.

BRASIL. Constituição (1988). Constituição da República Federativa do Brasil. Brasília, DF: Senado Federal, 1988.

Decreto $n^{\circ}$. 6.094, de 24 de abril de 2007. Dispõe sobre a implementação do Plano de Metas Compromisso Todos pela Educação, pela União Federal... Diário Oficial da União, Brasília, DF, 25 abr. 2007.

. Decreto $n^{\circ}$. 6.253, de 13 de novembro de 2007. Dispõe sobre o Fundo de Manutenção e Desenvolvimento da Educação Básica e de Valorização dos Profissionais da Educação - FUNDEB... Diário Oficial da União, Brasília, DF, 14 nov. 2007a. 
BRASIL. Emenda Constitucional nº. 14, de 12 de setembro de 1996. Modifica os artigos 34, 208, 211 e 212 da constituição federal e dá nova redação ao artigo 60 do ato das disposições constitucionais transitórias. Diário Oficial [da] República Federativa do Brasil, Brasília, DF, 13 set. 1996a.

Emenda Constitucional n ${ }^{\circ}$. 53, de 19 de dezembro de 2006. Dá nova redação aos arts. 70, 23, 30, 206, 208, 211 e 212 da Constituição Federal e ao art. 60 do Ato das Disposições Constitucionais Transitórias. Diário Oficial da União, Brasilia, DF, 9 mar. 2006.

Emenda Constitucional n ${ }^{\circ}$. 59, de 11 de novembro de 2009. Acrescenta $\S$ $3^{\circ}$ ao art. 76 do Ato das Disposições Constitucionais Transitórias para reduzir, anualmente, a partir do exercício de 2009, o percentual da Desvinculação das Receitas da União... Diário Oficial da União, Brasilia, DF, 12 nov. 2009.

Lei $n^{\circ}$. 4.024, de 20 de dezembro de 1961. Fixa as Diretrizes e Bases da Educação Nacional. Diário Oficial da União, Brasilia, DF, 27 dez. 1961.

. Lei $n^{\circ}$. 5.692, de 11 de agosto de 1971. Fixa Diretrizes e Bases para o ensino de $1^{\circ}$ e $2^{\circ}$ graus, e dá outras providências. . Diário Oficial [da] República Federativa do Brasil, Brasilia, DF, 12 ago. 1971.

Lei $n^{\circ} .9 .394$, de 20 de dezembro de 1996. Estabelece as diretrizes e bases da educação nacional. Diário Oficial [da] República Federativa do Brasil, Brasilia, DF, 23 dez. $1996 b$.

. Lei no. 10.172, de 9 de janeiro de 2001. Aprova o Plano Nacional de Educação e dá outras providências. Diário Oficial [da] República Federativa do Brasil, Brasilia, DF, 10 jan. 2001. Disponivel em: <http://www.planalto.gov.br/ ccivil_03/leis/leis_2001//10172.htm>. Acesso em: 4 nov. 2011.

Lei $n^{\circ}$. 10.861, de 14 de abril de 2004. Institui o Sistema Nacional de Avaliação da Educação Superior - SINAES e dá outras providências. Diário Oficial da União, Brasília, DF, 15 abr. 2004. Disponivel em: <http://www.planalto.gov.br/ ccivil_03/_ato2004-2006/2004/lei//10.861.htm>. Acesso em: 24 nov. 2011.

. Lei $n^{\circ} .11 .096$, de 13 de janeiro de 2005. Institui o o Programa Universidade para Todos - PROUNI, regula a atuação de entidades beneficentes de assistência social no ensino superior; altera a Lei ${ }^{0} 10.891$, de 9 de julho de 2004, e dá outras providências. Diário Oficial da União, Brasília, DF, 14 jan. 2005. Disponivel em: <http://www.planalto.gov.br/ccivil_03/_Ato2004-2006/2005/Lei/ L11096.htm>. Acesso em: 10 jun. 2010. 
BRASIL. Lei no. 11.494, de 20 de junho de 2007. Regulamenta o Fundo de Manutenção e Desenvolvimento da Educação Básica e de Valorização dos Profissionais da Educação - FUNDEB... Diário Oficial da União, Brasilia, DF, 21 jun. 2007b. Retificado no DOU de 22 jun. 2007.

- Ministério da Educação. Plano de metas compromisso todos pela educação: guia de programas. Brasilia: FNDE, 2007c. 86 p. Disponivel em: <http://planipolis.iiep.unesco.org/ upload/Brazil/BrazilGuiadosProgramasdoMEC.pdf>. Acesso em: 3 nov. 2011.

Ministério da Educação. Portaria Normativa n ${ }^{0}$. 2, de 26 de janeiro de 2010. Institui e regulamenta o Sistema de seleção unificada, sistema informatizado gerenciado pelo Ministério da Educação, para seleção de candidatos a vagas em cursos de graduação disponibilizadas pelas instituições públicas de educação superior dele participantes. Diário Oficial da União, Brasilia, DF, 27 jan. 2010. Seção 1, n. 18.

EDUCAÇÃO: mais educação. Brasilia, DF: MEC, 2007. Disponivel em: $<$ http://portal.mec.gov.br/>. Acesso em: 10 jun. 2010.

INEP. Prova Brasil e Saeb. Brasília, DF, 2009. Disponível em: <http:// provabrasil.inep.gov.br>. Acesso em: 25 nov. 2011.

LIMA, L.; AFONSO, A. J. Reformas da educação pública: democratização, modernização, neoliberalismo. Porto, PT: Afrontamento, 2002.

MULLER, P.; SUREL, Y. A análise das políticas públicas. Pelotas: Educat, 2004.

PERONI, V. Política educacional e o papel do Estado nos anos 1990. São Paulo: Xamã, 2003.

PNUD. A Atlas de Desenvolvimento Humano no Brasil. Brasília, DF, 1998. disponivel em: < http://www.pnud.org.br/atlas/>. Acesso em: 25 nov. 2011.

TODOS pela Educação. Brasilia, DF, 2010. Disponível em: <projetos_governanca_estatuto Todos pela educação. pdf >. Acesso em: 10 jun. 2010.

WERLE, F. O. C. A reinvenção da gestão dos sistemas de ensino: uma discussão do Plano de Desenvolviemnto da Educação 2007. Revista Educação em Questão, Natal, v. 35, n. 21, p. 98-119, maio/ago. 2009.

Recebido em: 14/03/2011

Aceito para publicação em: 30/08/2011 